\title{
Effects of Impaired Fasting Glucose on Aortic Elasticity
}

\author{
Authors \\ S. M. Dogan ${ }^{1}$, Z. Aktop ${ }^{1}$, M. Aydin ${ }^{1}$, T. Karabag ${ }^{1}$, M. R. Sayin ${ }^{1}$, H. M. Bilici ${ }^{1}$, H. Atmaca \\ Affiliations \\ ${ }^{1}$ Department of Cardiology, Faculty of Medicine, Zonguldak Karaelmas University \\ ${ }^{2}$ Department of Endocrinology and Metabolism, Faculty of Medicine, Zonguldak Karaelmas University
}

Key words
impaired fasting glucose
prediabetes
aortic stiffness
strain
distensibility
cardiovascular risk

received $\quad 12.12 .2011$

first decision 08.02.2012

accepted $\quad 15.02 .2012$

\section{Bibliography}

DOI http://dx.doi.org/

10.1055/s-0032-1306295

Published online:

May 10, 2012

Exp Clin Endocrinol Diabetes

2012; 120: 424-427

(C) . A. Barth Verlag in

Georg Thieme Verlag KG

Stuttgart · New York

ISSN 0947-7349

\section{Correspondence}

S. M. Dogan, MD

Bahcelievler M, Yildiz S,

Erdoganlar ap, 35/7

Zonguldak

Turkey

Tel.: +90/533/4802600

Fax: +90/372/2610155

smdogan@yahoo.com

\section{Abstract \\ $\nabla$}

Background: The pathophysiology of atherosclerosis development in patients with diabetes mellitus (DM) is similar to that in nondiabetics. However, atherosclerosis develops earlier and runs a rapid course in patients with diabetes. Aortic stiffness, strain and distensibility are the parameters used to assess an increase in arterial stiffness and can be measured by invasive and non-invasive methods.

Method: Aortic elastic properties were compared among patients with normal oral glucose tolerance test but impaired fasting glucose and healthy individuals. The study group consisted of 50 subjects with impaired fasting glucose who

\section{Introduction}

$\nabla$

Diabetes mellitus (DM) is a metabolic disorder with increased morbidity and mortality and increases the risk of coronary artery disease [1]. However, it is considered that the atherosclerotic process begins before the onset of overt diabetes. The evaluation of elastic properties of the aorta by non-invasive methods is an easily measurable method in the early diagnosis of atherosclerosis. It has been reported that arterial stiffness is a good predictor of cardiovascular mortality and morbidity [2]. The structural changes in the arterial wall as a result of diabetes have negative effects on arterial compliance and stiffness [3-5]. There are a number of studies reporting increased arterial stiffness in diabetes mellitus [6-11]. On the contrary, there are few studies investigating aortic elastic properties in patients with impaired oral glucose tolerance test (OGTT) [10-13]. In this study, aortic strain, distensibility and stiffness index indicating elastic properties of the aorta in patients with normal OGTT but impaired fasting glucose were compared to that in healthy subjects. had no known risk factors for atherosclerosis. The control group was composed of the same number of volunteers.

Results: It was found that aortic strain and distensibility were reduced $(8.78 \pm 4.3$ vs. $10.65 \pm 2.6$ $\mathrm{p}<0.01$ and $4.1 \pm 2.1$ vs. $5.1 \pm 1.7 \mathrm{p}<0.01$ respectively) and aortic stiffness index was significantly increased $(6.9 \pm 3.2$ vs. $5.01 \pm 1.6, p<0.0001)$ in patients with impaired fasting glucose compared to those in the control group.

Conclusions: It was demonstrated that aortic elasticity was impaired in those with impaired fasting glucose, which indicates that these patients should be kept under close follow-up for cardiovascular events.

\section{Materials and Methods}

$\nabla$

50 patients ( 23 male, age $43 \pm 9$ ) who were admitted to our clinic for various reasons and who had normal OGTT but impaired fasting glucose with values between $100-126 \mathrm{mg} / \mathrm{dl}$ on routine biochemical tests were enrolled in this study. The exclusion criteria were patients with hypertension, coronary artery disease, and cardiac valve disease, a history of cerebrovascular disease, collagen tissue disease, dyslipidemia, tobacco and alcohol use and impaired OGTT. The control group consisted of 50 age and sex matched healthy subjects ( 29 male, age $41 \pm 9$ ) with fasting blood glucose below $100 \mathrm{mg} / \mathrm{dl}$. All patients were imaged in the left lateral decubitus position using a GE VingMed Vivid FiVe echocardiography device. M-Mode images were obtained at a level of $3 \mathrm{~cm}$ proximal to the aortic valve from a parasternal long axis view. Rhythm recordings were made during echocardiographic examination in all patients. The end diastolic aortic diameter was measured at the peak of QRS in M-mode images. Maximum aortic wall thickness was also measured in the same cycle and used as aortic 
Table 1 Demographic Datas.

\begin{tabular}{|c|c|c|c|}
\hline & $\begin{array}{l}\text { Study group } \\
(n=50)\end{array}$ & $\begin{array}{l}\text { Control group } \\
(n=50)\end{array}$ & $\mathbf{p}$ \\
\hline age & $43 \pm 9$ & $41 \pm 9$ & NS \\
\hline male $(\%)$ & $23(46)$ & $29(58)$ & NS \\
\hline $\begin{array}{l}\text { systolic blood pressure } \\
\text { (mmHg) }\end{array}$ & $114 \pm 11$ & $112 \pm 13$ & NS \\
\hline $\begin{array}{l}\text { diastolic blood pressure } \\
\text { (mmHg) }\end{array}$ & $69 \pm 7$ & $68 \pm 9$ & NS \\
\hline $\begin{array}{l}\text { resting heart rate } \\
\text { (beat/min) }\end{array}$ & $77 \pm 11$ & $74 \pm 12$ & NS \\
\hline $\mathrm{BMI}\left(\mathrm{kg} / \mathrm{m}^{2}\right)$ & $25.64 \pm 2.04$ & $25.81 \pm 1.74$ & NS \\
\hline $\mathrm{BSA}\left(\mathrm{m}^{2}\right)$ & $1.85 \pm 0.13$ & $1.82 \pm 0.09$ & NS \\
\hline total cholesterol (mg/dl) & $196 \pm 41$ & $197 \pm 42$ & NS \\
\hline triglyceride (mg/dl) & $137 \pm 89$ & $117 \pm 50$ & NS \\
\hline HDL cholesterol (mg/dl) & $48 \pm 13$ & $45 \pm 11$ & NS \\
\hline LDL cholesterol (mg/dl) & $121 \pm 38$ & $129 \pm 40$ & NS \\
\hline
\end{tabular}

BMI: Body mass index, BSA: Body surface area, NS: Not significant

systolic diameter. After echocardiographic examination, blood pressure was measured non-invasively in the brachial artery in all patients. Based on the obtained data, aortic strain, aortic stiffness and aortic distensibility were calculated using the formula below [11]:

- Strain (\%)=100×(aortic systolic diameter - aortic diastolic diameter)/Aortic diastolic diameter

- Distensibility $\left(\mathrm{cm}^{2} \times d y n^{-1} \times 10^{-6}\right)=(2 \times$ strain $) /($ Systolic blood pressure - diastolic blood pressure)

- Stiffness index=Ln (Systolic blood pressure/diastolic blood pressure)/[(Aortic systolic diameter - aortic diastolic diameter)/Aortic diastolic diameter]

Data analyis was performed using SPSS (Statistical Package for Social Sciences) for Windows 15 (SPSS Inc. Chicago, IL, USA). Quantitative data were analyzed using the Student-t test and qualitative data Chi-square test. Pearson's correlation analysis was used for correlation analyses. The results were evaluated at a significance level of $\mathrm{p}<0.05$ with a confidence interval Data analysis was performed using SPSS (Statistical Package for Social Sciences) for Windows 15 (SPSS Inc. Chicago, IL, USA). Quantitative data were analyzed using the student- test and qualitative of $95 \%$.

The study protocol was approved by the university ethics committee of our institution and written consent was taken from all participants.

\section{Reproducibility}

Relatively low intra- and interobserver variability values (8-10\%) for TDI measurements were reported previously from our laboratory [12].

\section{Results}

$\nabla$

There were no statistically significant differences in age, sex, systolic and diastolic blood pressures, pulse rate, body mass index and body surface area between the study and control groups ( $\bullet$ Table $\mathbf{1}$ ).

Aortic stiffness index was found to be increased in the study group compared to the control group $(6.9 \pm 3.2$ vs. $5.01 \pm 1.6)$ $(\mathrm{p}<0.0001)(\diamond$ Table 2$)$.
Table 2 Aortic Parameters.

\begin{tabular}{|llll|}
\hline & $\begin{array}{l}\text { Study group } \\
(\mathbf{n}=\mathbf{5 0 )}\end{array}$ & $\begin{array}{l}\text { Control group } \\
(\mathbf{n}=\mathbf{5 0 )}\end{array}$ & P \\
\hline aortic strain (\%) & $8.78 \pm 4.3$ & $10.65 \pm 2.6$ & $<0.01$ \\
\hline aortic stiffness index & $6.90 \pm 3.2$ & $5.01 \pm 1.6$ & $<0.001$ \\
\hline $\begin{array}{l}\text { aortic distensibility } \\
\mathbf{c m}^{\mathbf{2}} \times \mathbf{d y n}^{-1} \times \mathbf{1 0}^{-\mathbf{6}}\end{array}$ & $4.1 \pm 2.1$ & $5.1 \pm 1.7$ & $<0.01$ \\
\hline
\end{tabular}

Aortic strain and aortic distensibility was lower in the study group as compared to the control group $(8.78 \pm 4.3$ vs. $10.65 \pm 2.6$ and $4.1 \pm 2.1$ vs. $5.1 \pm 1.7$, respectively) ( $<<0.01$ and $\mathrm{p}<0.01$, respectively) ( $\bullet$ Table 2 ).

There was no relationship between age and aortic strain, aortic stiffness and aortic distensibility values. No relationship was found between the measured parameters and blood glucose levels.

\section{Discussion}

In this study, we found that arterial stiffness index was increased but aortic strain and distensibility were decreased in subjects with impaired fasting glucose compared to the control group. As far as we are aware, this is the first study in the literature evaluating elastic properties of the aorta by echocardiography in the patient group with normal OGTT but impaired fasting glucose. Aortic stiffness is influenced by a variety of conditions. It is known that increased arterial stiffness is an independent predictor of cardiovascular mortality and morbidity [13-16]. It was demonstrated that aortic stiffness increased with age in groups matched for all characteristics but age [17]. Structural changes in elastin and collagen fibrils of the arterial wall during aging may be responsible for the increased stiffness. The negative effects of aging on aortic elastic properties were excluded since the patients included in this study were relatively homogenous in age.

A study by Toutouzas et al. demonstrated that elastic properties of the aorta were impaired associated with the duration of diabetes [13]. In the same study it was found that aortic elasticity was decreased as fasting blood glucose levels increased [13]. In this study, patients with impaired fasting glucose and healthy subjects were compared and no relationship was found between impaired fasting glucose levels and elastic properties of the aorta, which might be caused by the fact that the patients were newly diagnosed and thus, the time from the onset of impaired fasting glucose differed among patients.

Another condition that is closely related to aortic elastic properties is sex. Increased arterial stiffness is less common in women than in men. However, this is the case with premenopausal women. The difference between the sexes decreases in postmenopausal period [18-20]. In addition, it has been demonstrated that hormone replacement therapy increases arterial compliance in postmenopausal period [21]. There was no statistical difference in the number of males and females between the groups. The groups were compared free of the effects of sex on aortic stiffness. The effects of menopause on elastic properties of the aorta could not be evaluated since a sufficient number for statistical analysis could not be obtained when women with impaired fasting glucose were categorized as premenopausal and postmenopausal. 
Hypertension may also lead to impairment of the elastic properties of the aorta [13]. The arterial wall stress caused by high blood pressure leads to atherosclerosis and structural changes. Some changes occur to the collagen and elastin fibers of the arterial wall as a result of the mechanical effect and arterial stiffness increases $[22,23]$. Since hypertension was an exclusion criteria in this study, we did not investigate the relationship between high blood pressure and arterial stiffness. Additionally, since systolic blood pressure, diastolic blood pressure and resting heart rates were similar in our patients by routine physical examination, we can say that the subjects in both groups have similar hemodynamics.

The detection of aortic stiffness by echocardiography indicates increased likelihood of coronary artery disease in patients with impaired elastic properties but does not provide a definitive diagnosis [24]. The presence of a statistically significant difference in elastic properties of the aorta between patients with impaired fasting glucose and the control group may suggest that impaired fasting glucose causes a significant impairment in elastic properties of the aorta and the risk for coronary artery disease is higher in these patients compared to normal individuals. In a study by Xu et al., the group with impaired fasting glucose, and the group with impaired OGTT and patients with normal plasma glucose were compared for an increase in arterial stiffness. The brachial-ankle pulse wave velocity and pulse pressure were used as the indicators of arterial stiffness. Both pre-diabetic groups had greater arterial stiffness compared to the control group. In the same study, patients with impaired glucose tolerance had greater arterial stiffness compared to those with impaired fasting glucose, which was attributed to those patients' being more insulin resistant [15]. In this study, the group with impaired fasting glucose and the control group with normal plasma glucose were compared. However, since the patients with impaired glucose tolerance were older with a worse lipid profile compared to those with impaired fasting glucose in the study by Xu et al., it should be kept in mind that they may also cause aortic stiffness. In this study, the groups had similar age and lipid profiles. Unlike the mentioned study, aortic strain, aortic distensibility and $\beta$-stiffness index were used for the prediction of arterial stiffness. However, we also obtained findings consistent with those of Xu et al.

In another study by Rerkpattanapipat et al., 2240 subjects with normal fasting glucose, 845 with impaired fasting glucose and 414 with diabetes, all aged $45-85$ years, were compared for total arterial stiffness, proximal thoracic aortic stiffness, left ventricular mass and left ventricular hypertrophy. The results of the mentioned study showed no statistically significant difference in aortic stiffness, left ventricular mass and left ventricular hypertrophy between the group with impaired fasting glucose and the group with normal fasting glucose. There was an increase in aortic stiffness, left ventricular mass and left ventricular hypertrophy in patients with diabetes compared to subjects with normal fasting glucose [25]. Unlike the mentioned study, no difference was found in arterial stiffness increase between the group with impaired fasting glucose and the control group. The difference between the results is likely to be caused by the method used.

In a study by Topsakal et al., 47 patients with impaired glucose tolerance who had no coronary artery disease or other cardiovascular risk factors and 32 healthy subjects were compared. Prediabetic patients had increased aortic stiffness and decreased elasticity compared to the controls and the findings were evalu- ated by tissue Doppler echocardiography [14]. Topsakal et al. compared patients with impaired OGTT in the prediabetic group and the control group. However, in this study, patients with impaired fasting glucose were compared with normal subjects. The results of our study are consistent with those by Topsakal et al. and are noteworthy in that it demonstrated that the impairment of elastic properties of the aorta starts in the impaired fasting glucose stage, an earlier stage than tolerance impairment.

\section{Limitations}

There are some limitations to this study. The first is the small number of patients. Second, the extent of the impairment of elastic properties of the aorta associated with the duration of impaired fasting glucose could not be elucidated since we were unaware of the duration of impaired fasting glucose. We may be able to answer this question by repeating the examinations of the same patient group after a while. Third, Dietary habit, one of the external factors for increased arterial stiffness, has an important effect. It has been demonstrated that saturated fatty acids and western style diet rich in carbohydrate play role in the development of arterial stiffness [26]. Also, a diet rich in omega 3 fatty acids has preventive effects against arterial stiffness increase as in coronary artery disease has been reported [9]. Our patients were not questioned specifically about their diets, however, the patients in the patient and control groups can be regarded as identical in terms of diet because they live in the same region. However, the region itself does not allow to judge about the dietary intake, this also depends on income and social status.

\section{Conclusion}

$\nabla$

In conclusion, this study supports that atherosclerosis starts with the impaired fasting glucose stage in the diabetic process. The cardiovascular risk increases in the impaired fasting glucose stage and the demonstration of impaired aortic elasticity by this study indicates the necessity for a close cardiovascular followup for in these patients. The detection of coronary artery disease in the asymptomatic period and early planning of the required treatment strategies contribute to patient mortality and morbidity as well as to economy in the context of preventive medicine.

\section{Conflict of Interest: None.}

\section{References}

1 Ugur-Altun B, Altun A, Guldiken S et al. Silent myocardial ischemia in middle-aged asymptomatic patients with type 2 diabetes in Turkish population. Angiology 2007; 58: 535-542

2 van Popele NM, Grobbee DE, Bots ML et al. Association between arterial stiffness and atherosclerosis: the Rotterdam Study. Stroke 2001; 32: 454-460

3 Henry RM, Kostense PJ, Spijkerman AM et al. Arterial stiffness increases with deteriorating glucose tolerance status: the Hoorn Study. Circulation 2003; 107: 2089-2095

4 St John SM. Aortic stiffness: a predictor of acute coronary events? Eur Heart J 2000; 21: 342-344

5 Stefanadis C, Dernellis J, Tsiamis E et al. Aortic stiffness as a risk factor for recurrent acute coronary events in patients with ischaemic heart disease. Eur Heart J 2000; 21: 390-396 
6 Cosson S, Kevorkian JP. Left ventricular diastolic dysfunction: an early sign of diabetic cardiomyopathy? Diabetes Metab 2003; 29: 455-466

7 Eren M, Gorgulu S, Uslu N et al. Relation between aortic stiffness and left ventricular diastolic function in patients with hypertension, diabetes, or both. Heart 2004; 90: 37-43

8 Freedman DS, Gruchow HW, Bamrah VS et al. Diabetes mellitus and arteriographically-documented coronary artery disease. J Clin Epidemiol 1988; 41: 659-668

9 Monnier VM, Vishwanath V, Frank KE et al. Relation between complications of type I diabetes mellitus and collagen-linked fluorescence. $\mathrm{N}$ Engl J Med 1986; 314: 403-408

10 Salomaa $V$, Riley $W$, Kark JD et al. Non-insulin-dependent diabetes mellitus and fasting glucose and insulin concentrations are associated with arterial stiffness indexes. The ARIC Study. Atherosclerosis Risk in Communities Study. Circulation 1995; 91: 1432-1443

11 Wilkenshoff UM, Sovany A, Wigström L et al. Regional Mean Systolic Myocardial Velocity Estimation by Real-Time Color Doppler Myocardial Imaging: A New Technique for Quantifying Regional Systolic Function. J Am Soc Echocardiography July 1998; 11 (7): 683-692

12 Dogan S, Aydin M, Gursurer M et al. Prediction of subclinical left ventricular dysfunction with strain rate imaging in patients with mild to moderate rheumatic mitral stenosis. J Am Soc Echocardiography Mar 2006; 19 (3): 243-248

13 Toutouzas K, Stefanadis C, Tsiamis E et al. Aortic pressure-diameter relation in patients with non-insulin dependent diabetes mellitus: new insights. Diabetologia 2000; 43: 1070-1075

14 Topsakal R, Bayram F, Caliskan M. Glukoz tolerans bozukluğu olan hastalarda aortun elastik özelliklerinin konvansiyonel ve renkli doku dopler ekokardiyografiyle değerlendirilmesi. Türk Kardiyoloji Derneği Arşivi 2004; 32: 16-22

$15 \mathrm{Xu}$ L, Jiang CQ Lam TH et al. Impact of impaired fasting glucose and impaired glucose tolerance on arterial stiffness in an older Chinese population: the Guangzhou Biobank Cohort Study-CVD. Metabolism Mar 2009; 59 (3): 367-372
16 Arnett DK, Evans GW, Riley WA. Arterial stiffness: a new cardiovascular risk factor? Am J Epidemiol 1994; 140: 669-682

17 Gary FM, Helen P, Emelia JB et al. Changes in arterial stiffness and wave reflection with advancing age in healthy men and women. Hypertension 2004; 43: 1239-1245

18 Gudbrandsson T, Julius $S$, Krause $L$ et al. Correlates of the estimated arterial compliance in the population of Tecumseh, Michigan. Blood Press 1992; 1: 27-34

19 Lehmann ED, Gosling RG, Sonksen PH. Arterial wall compliance in diabetes. Diabet Med 1992; 9: 114-119

20 Vaitkevicius PV, Fleg JL, Engel JH et al. Effects of age and aerobic capacity on arterial stiffness in healthy adults. Circulation 1993; 88: 1456-1462

21 Rajkumar C, Kingwell BA, Cameron JD et al. Hormonal therapy increases arterial compliance in postmenopausal women. J Am Coll Cardiol 1997; 30: $350-356$

22 Amar J, Ruidavets JB, Chamontin B et al. Arterial stiffness and cardiovascular risk factors in a population-based study. J Hypertens 2001; 19: $381-387$

23 Schram MT, Kostense PJ, van Dijk RA et al. Diabetes, pulse pressure and cardiovascular mortality: the Hoorn Study. J Hypertens 2002; 20: $1743-1751$

24 Cameron JD, Jennings GL, Dart AM. Systemic arterial compliance is decreased in newly-diagnosed patients with coronary heart disease: implications for prediction of risk. J Cardiovasc Risk 1996; 3: 495-500

25 Rerkpattanapipat P, D'Agostino RB Jr, Link KM et al. Location of arterial stiffening differs in those with impaired fasting glucose versus diabetes: implications for left ventricular hypertrophy from the MultiEthnic Study of Atherosclerosis. Diabetes 2009; 58: 946-953

26 Dart AM, Qi XL. Determinants of arterial stiffness in Chinese migrants to Australia. Atherosclerosis 1995; 117: 263-272 